\title{
Severe autogenously fecal peritonitis in Wistar rats with permanent bilateral carotid occlusion. Response to intra peritoneal moxifloxacin combined with dexamethasone ${ }^{1}$
}

\author{
Maria Cecília Santos Cavalcanti Melo ${ }^{\mathrm{I}}$, Diego Nery Benevides Gadelha" ${ }^{\mathrm{II}}$, Thárcia Kiara Beserra Oliveira ${ }^{\mathrm{III}}$, Carlos Teixeira Brandt ${ }^{\mathrm{IV}}$ \\ IFellow PhD degree, Postgraduate Program in Surgery, Health Sciences Center, Federal University of Pernambuco (UFPE). Assistant Professor, \\ Department of Ophthalmology, Campina Grande Faculty of Medicine (FCM), Campina Grande-PB, Brazil. Acquisition and interpretation of data, \\ manuscript writing.

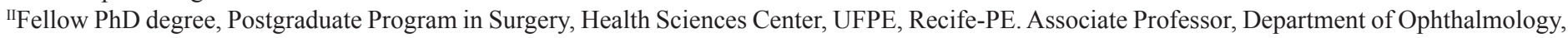 \\ FCM, Campina Grande-PB, Brazil. Manuscript writing, critical revision. \\ III Fellow Master Degree in Agricultural Engineering, Federal Campina Grande University (UFCG)-PB, Campina Grande-PB, Brazil. Acquisition and \\ interpretation of data. \\ ${ }^{\text {IV }} \mathrm{PhD}$, Head Professor, Scientific Methodology and Pediatric Surgery, UFPE, Recife-PE. Coordinator, FCM, Campina Grande-PB, Brazil. Interpretation \\ of data, English version. final revision
}

\begin{abstract}
PURPOSE: To evaluate the treatment outcome of severe peritonitis in rats submitted to permanent bilateral carotid occlusion (PBCO). METHODS: Sixteen Wistar rats (mean age of 8.5 months) with PBCO underwent autogenously fecal peritonitis, and were treated with moxifloxacin combined with dexamethasone, and followed-up for 45 days. Ten rats (mean age five months) without PBCO were used as a control group. The variables were expressed by their mean and standard error of the mean (SEM). $\mathrm{p}<0.05$ was used for rejecting the null hypothesis. The study was approved by the Ethics Committee.

RESULTS: There was a significant increase $(\mathrm{p}=0.0002)$ in the mortality and morbidity in older rats that underwent PBCO (study group). However, even among the survival rats presenting with severe residual abscesses both in the abdomen and thorax cavities, they present an almost normal life.

CONCLUSIONS: The treatment of severe autogenously fecal peritonitis with intraperitoneal moxifloxacin combined with dexamethasone was very effective in young rats without permanent bilateral carotid occlusion. The treatment reached reasonable results in older rats with $\mathrm{PBCO}$, even considering residual abscesses on abdomen and thorax. Older age was the greater risk factor for the outcome of the treatment of severe peritonitis. Sepsis remains a challenging situation, especially in elderly.
\end{abstract}

Key words: Peritonitis. Quinolones. Dexamethasone. Therapy. Rats. 


\section{Introduction}

Fluor quinolones have been successfully used to treat multidrug-resistant and severe Gram-negative infections without major effects in human infants and neonatal rats ${ }^{1,2}$. Some of this sepsis comes from secondary peritonitis, which still is a great challenge for medical management. There is a vast arsenal of antimicrobial substances for using in human beings. These drugs, both systemic and local could have important side effects, which have been under investigation, due to bad outcomes in several patients ${ }^{3-8}$.

Adhesion and abscess formation increase mortality and morbidity after peritonitis. Several therapeutically approaches have been used for dealing with these severe problems, including intraperitoneal substances ${ }^{4-9}$.

Combined moxifloxacin/dexamethasone formulation for topical prophylaxis and reduction of inflammation in phacoemulsification has been proved ${ }^{10-12}$. On the other hand, the efficacy of moxifloxacin on the management of complicated intraabdominal infections and sepsis has also been positive $\mathrm{e}^{7,13,14}$. However, its use inside the abdominal cavity for severe peritonitis has not yet been tested. Moreover the association with dexamethasone that is a powerful inhibitor of TNF- $\alpha$ cytokine through inhibition of NF- $\kappa \mathrm{B}$, which is a gene regulator of multiple pro-inflammatory cytokines ${ }^{15}$ could improve the treatment outcome of this life threatening condition.

Assuming the absorptive similarity of these substances, from plasma into the peritoneum ${ }^{16}$ as compared with that in the conjunctiva $^{17}$, this study aimed at to investigate the action of intraperitoneal moxifloxacin combined with dexamethasone on the morbidity and mortality in a fecal autogenously model of peritonitis in rats that underwent permanent bilateral carotid occlusion (PBCO).

\section{Methods}

The research was approved by the Institutional Research Ethics Committee of Animal Experimentation of FCM, Campina Grande-PB.

Adult Wistar rats (Rattus norvegicus, rodentia mammalia) from the animal house were used for this study. They were housed in polypropylene cages, four animals per cage, under standard light/dark conditions (lights on 7:00, off 19:00) with food pellets and water ad libitum.

Chronic cerebral hypo perfusion was induced by $\mathrm{PBCO}^{18,19}$, in 16 rats with mean age of two months (study group). At the time of peritonitis induction the mean age was 8.5 months and the mean weight was 457 grams (minimum $277 \mathrm{~g}$ and maximum $505 \mathrm{~g}$ ). The animal with minimum weight presented with teeth deformity.

The animals were anesthetized with ketamine hydrochloride $(50 \mathrm{mg} / \mathrm{kg}$ - ip) and xilasine (10 mg/kg -ip). The common carotid arteries were exposed via a ventral midline incision, carefully separated from their sheaths and vagus nerves, and permanently doubly tied with $5 / 0$ silk suture approximately 8 to $10 \mathrm{~mm}$ below the origin of the external carotid artery.

Peritonitis was induced, in these 16 rats, after 6.5 months post-operative $\mathrm{PBCO}$, by intra-peritoneal inoculation of a $10 \%$ suspension of autogenously feces. Two grams of stools were collected for each own individually rat and dissolved in $20 \mathrm{ml}$ of $0.9 \%$ saline solution. This mixture was homogenized and filtered through gauze in order to remove large particles. It was injected $6 \mathrm{ml} / \mathrm{kg}$ of the suspension in the intra-peritoneal cavity, in the left iliac quadrant, using a $30 \times 12 \mathrm{~mm}$ needle. The rats had to have regular bowel habits and no macroscopic feces changes (blood, mucus or pus).

After eight days following induction of autogenously fecal peritonitis it was injected intraperitonially (ip) a combination of moxifloxacin at a doses of $15 \mathrm{mg} / \mathrm{kg}$ and dexamethasone at a doses of $2.5 \mathrm{mg} / \mathrm{kg}$ as an eye drop solution (moxifloxacin cloridrat $0,5 \%$ and dexamethasone phosphate $0.1 \%$ ).

Ten Wistar rats with mean age of five months were enrolled in the investigation (control group). The mean weight of these rats was 417 grams (minimum $386 \mathrm{~g}$ and maximum $464 \mathrm{~g}$ ). They underwent the same treatment protocol for severe autogenously peritonitis and antibiotics management.

The animals were observed, by the veterinary, as regard to: activity, body temperature, respiratory rate and hair status, with the goal of obtaining signs of serious infection.

The animals that died after antibiotics treatment and those that survived for 45 days after fecal peritonitis induction were euthanized for abdominal and thorax inspection for: abscess identification, adhesions and macroscopic infection signs like pus inside or in the solid organs. Photos were taken for documentation.

At the time end of observation, one milliliter of blood was aspirated from the right ventricle and injected into the blood culture vials and sent for microbiology lab.

The blood culture vials were incubated at $35 \pm 2{ }^{\circ} \mathrm{C}$ after $24 \mathrm{~h}$ and cultivated in agar blood. The bacterioscopy was done by Gram. When the bacterioscopic exam was positive, it was followed by biochemical identification; if not the sample returned to the oven at $35 \pm 2{ }^{\circ} \mathrm{C}$ in $\mathrm{CO}_{2}$. After $48 \mathrm{~h}$, it was again cultivated in blood agar for seven days, and then a drop was cultivated in agar chocolate. If positive the case it was sent for final identification. 
The colony numbers results were expressed as colony forming units per $\mathrm{ml}(\mathrm{CFU} / \mathrm{ml})$.

To stratify morbidity and mortality it was used a modified protocol validated previously ${ }^{20}$ :

Score 0 - Animals that died of septic shock in the first 24 hours after induction of fecal peritonitis;

Score 1 - Animals that died from septic shock between 24 and 48 hours after induction of peritonitis;

Score 2 - Animals that died between 48 hours and eight days after the induction of peritonitis, with obvious clinical signs of serious infection;

Score 3 - Animals that died between eight and 45 days after the induction of peritonitis, with obvious clinical signs of serious infection;

Score 4 - Animals that survived until $45^{\text {th }}$ day, but still have positive blood culture and after the euthanasia have abscesses inside the abdomen and thorax cavities.

Score 5 - Animals that survived until $45^{\text {th }}$ day after the induction of fecal peritonitis and still have positive blood culture and after the euthanasia, abscesses inside the abdomen and thorax cavities were observed;

Score 6 - Animals that survived until $45^{\text {th }}$ day after the induction of fecal peritonitis and still have positive blood culture and after the euthanasia, abscesses only inside the abdomen cavity were observed;

Score 7 - Animals that survived until $45^{\text {th }}$ day after the induction of fecal peritonitis but has negative blood culture and after the euthanasia, abscesses inside the abdomen and thorax cavities were observed;

Score 8 - Animals that survived until $45^{\text {th }}$ day after the induction of fecal peritonitis, have negative blood culture and after the euthanasia, however abscesses were only observed inside the abdomen cavity;

Score 9 - Animals that survived until $45^{\text {th }}$ day after the induction of fecal peritonitis, have negative blood culture and after the euthanasia, and only one small abscess was observed inside the abdomen cavity;

Score 10 - Animals that survived until $45^{\text {th }}$ day after the induction of fecal peritonitis, have negative blood culture and after the euthanasia, abscesses inside the abdomen and thorax cavities were not observed.

The quantitative variables were expressed by their mean and standard error of the mean (SEM) and the qualitative by their frequencies. For assessing the mean difference it was used de unpaired " $t$ " test (Welch corrected) and the Tukey-Kramer multiple comparisons test. The significance level was $95 \%(\mathrm{p} \leq 0.05)$.

\section{Results}

One malnourished rat from the study group died on the $4^{\text {th }}$ day after the peritonitis induction. Thus, it received no medication. It was observed that it had two deformed teeth, which prevented their take of food. Thus, only 15 animals were included in the statistical analysis for morbidity.

One animal developed orchitis and abscess in the scrotum and other developed ascites. Both animals were in the study group.

Taking into account only 13 animals that survived 45 days since peritonitis induction, and receiving moxifloxacin combined with dexamethasone (study group), one can observe that there was a reduction of the mean weight after severe peritonitis. Following the antibiotics treatment there was a progressive stabilization of the weight, which returned to normal values at the end of the study (Table 1).

TABLE 1 - Multiple comparisons Tukey-Kramer test for weight before peritonitis inductions, eight days following this procedure, three weeks after antibiotics treatment and at end of the study $(n=13)$.

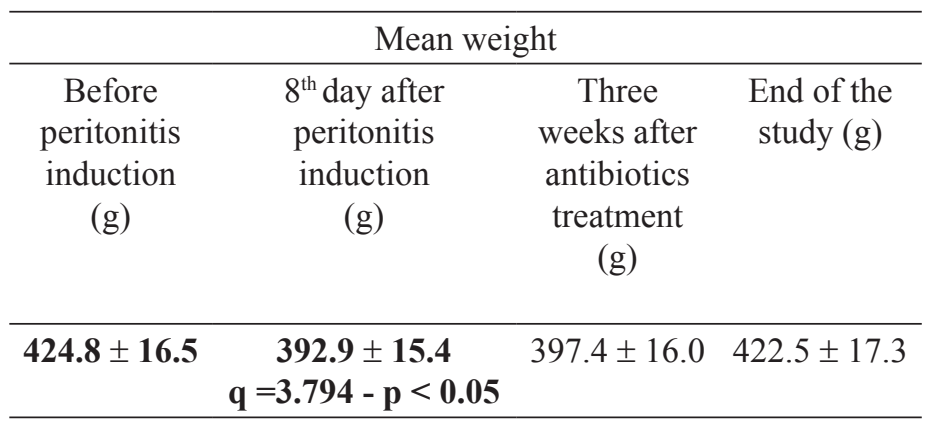

There was no significant difference in the means of weight in the control group all along the study period.

The mean scores for morbidity and mortality of the control animals was significantly greater than those of the study group $\left(\chi_{\mathrm{c}}=8.3 \pm 0.61\right.$ versus $\left.\chi_{\mathrm{s}} 4.8 \pm 0.38-\mathrm{p}=0.0002\right)$ (Table 2$)$.

TABLE 2 - Summary data of the scores of both groups.

\begin{tabular}{ccc}
\hline $\begin{array}{c}\text { Morbidity and mortality } \\
\text { scores (parameters) }\end{array}$ & Study group & $\begin{array}{c}\text { Control } \\
\text { group }\end{array}$ \\
\hline Mean & 4.8 & 8.3 \\
$\mathrm{n}$ & 15 & 10 \\
Standard deviation & 1.474 & 1.947 \\
Standard error of the mean & 0.380 & 0.6155 \\
Minimum & 1 & 5 \\
Maximum & 6 & 10 \\
Median & 5 & 9 \\
Lower 95\% CI & 3.984 & 6.908 \\
Upper 95\% CI & 5.616 & 9.692 \\
\hline
\end{tabular}


It was observed, when the surgical inventory after euthanasia was performed, that rats in the study group although presenting with severe infected lesions both in the abdomen and thorax had almost no clinical signs of disease. After 45 days post peritonitis induction, or 37 days since intra peritoneal antibiotics, they were gaining weight, very active, eating well, and presenting no signs of changes in the animal fur or in their behaviors (Figures 1 to 6 ).

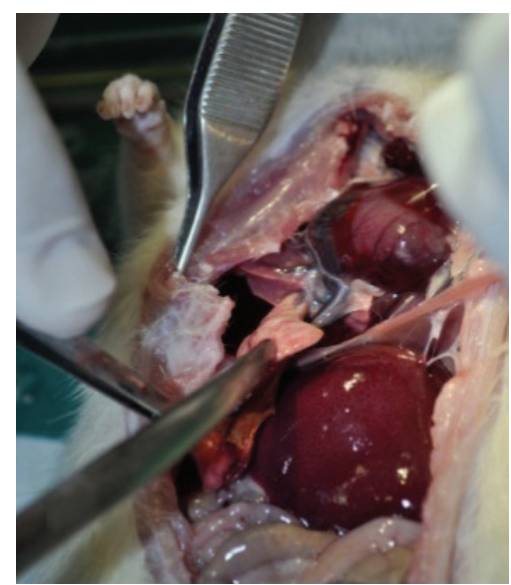

FIGURE 1 - Fibrotic residual inferior right lung lobe as result of severe infection. The animal had no signs of respiratory distress.

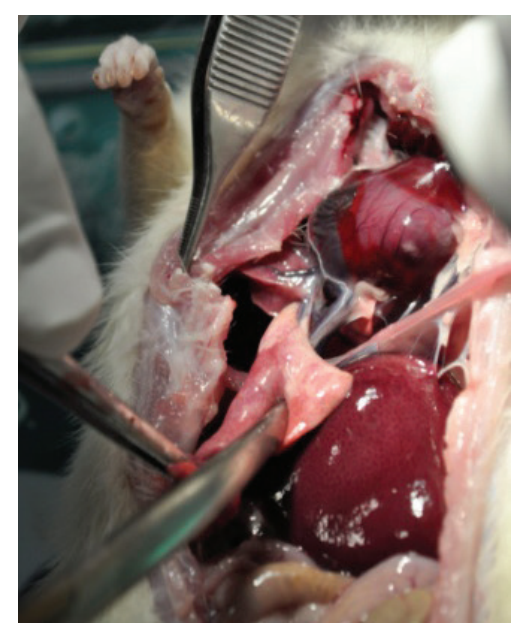

FIGURE 2 - Partial fibrotic inferior right lung lobe as result of severe infection. Animal with no respiratory distress.

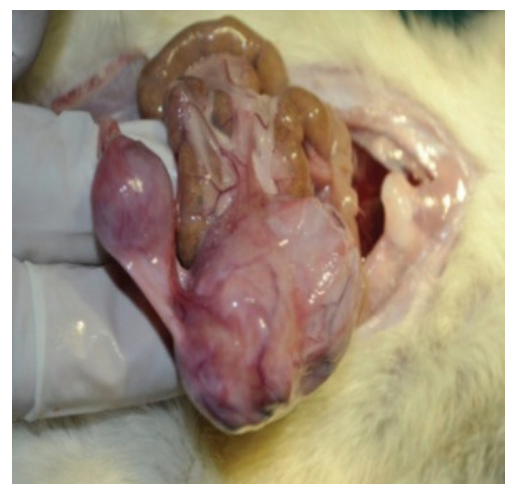

FIGURE 3 - Large and small abscesses inside the abdominal cavity. Animal with normal bowel movements.

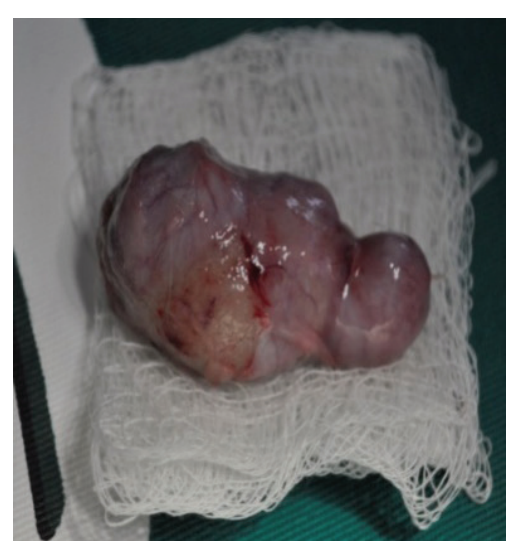

FIGURE 4 - Isolated blocked abscess removed from the mesentery.

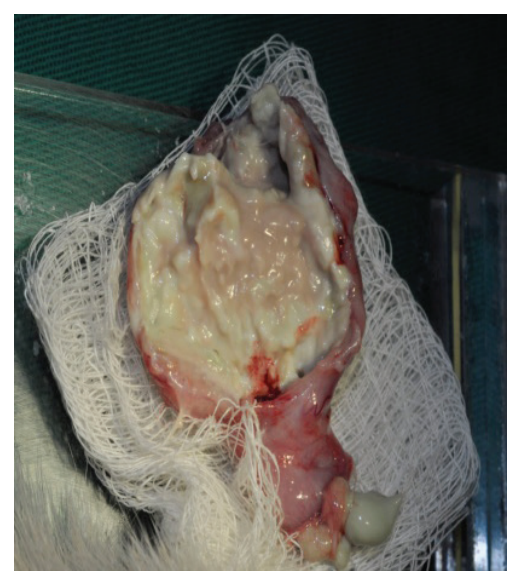

FIGURE 5 - Sterile material inside the intra-abdominal abscess.

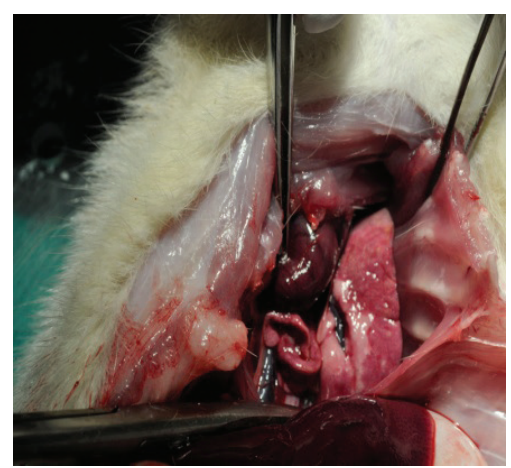

FIGURE 6 - Fibrotic tissue as a residual lung abscess of the left lung lobe. Animal with no respiratory distress.

\section{Discussion}

Moxifloxacin, used as monotherapy, has been beneficial in secondary severe intra-abdominal sepsis with high clinical and bacteriological efficacies in hospitalized patients; even with polyorganic insufficiency ${ }^{7}$.This fourth generation fluor quinolone promotes control of sepsis and septic-shock and has a good penetration from the blood into the peritoneal cavity, aiming to control severe peritonitis ${ }^{21-26}$. However, its use inside the peritoneal cavity has not yet 
been tested. This fluor quinolone combined with dexamethasone has also been used in controlling infection post eye surgery ${ }^{10,11}$.

Moxifloxacin in association with other antimicrobial substances and antibiotics seems not to increase its efficacy ${ }^{27,28}$.

There are few reports on the action of intra peritoneal drugs in patients or animal models of polymicrobial sepsis due to peritonitis. Additionally, the follow-up is usually short in time, and there is no mention to mean age of the animals ${ }^{29-32}$. Almost all of these studies lend no support to concept that antibiotics or others substances produce reduction of the morbidity and mortality for sepsis secondary to peritonitis ${ }^{9,30}$.

It was evident that the outcome of the rats from the control group was better than the ones in the study group. There are at least two factors that may be involved in the possible explanation for these findings. First of all, the rats of the control group were younger than the ones in the study group. Secondly, they had not undergone PBCO. One can assume, although there is no hard scientific evidence, that neuronal death after this surgical procedure may be associated with a change in the immune response of these animals. On the other hand it is well known that immune response decrease as the rat gets older, and PBCO may be associated with forced senescence.

Other interesting observation, in the present investigation, was the early death after peritonitis induction, of one malnourished rat. Although it could normally be expected, since the used volume of the autogenously fecal suspension $(6 \mathrm{ml} / \mathrm{kg}$ of rat) was greater than previous study ${ }^{9}$, and can kill a normal rat, it is likely that in this animal malnutrition was related with this bad result. Thus, the finding is in accordance with the knowledge that this condition is associated with impaired immune response in human beings. On the other hand, we assume that this animal should be excluded from this investigation because it presented with a characteristics that could interfere with the outcome (confounding variable).

Overall, the outcome of rats, from both groups, with severe peritonitis was good as compared with similar study ${ }^{9}$, using other intra peritoneal substances. Furthermore, the follow-up, post intraperitoneal treatment, in the present study was longer than others performed in mice ${ }^{31}$ and rats $^{32}$.

From the results it is interesting to foresee the use the information of the present study for translational purpose for adjunctive measure in treating human beings with sepsis due to secondary peritonitis.

\section{Conclusions}

The action of intra peritoneal moxifloxacin combined with dexamethasone on the morbidity and mortality, in a fecal autogenously model of peritonitis in rats that underwent permanent bilateral carotid occlusion, and the control ones was good and deserves further investigation in animal model or in human beings with sepsis due to secondary peritonitis. This condition remains a very challenging situation, associated still with a high morbidity and mortality, especially in elderly.

\section{References}

1. Leibovitz E. The use of fluoroquinolones in children. Curr Opin Pediatr. 2006;18:64-70.

2. Nolwenn Le Saché N, Baud O, Julien Pansiot J, Pham H, Biran V, Nadège Brunel-MeunierN, Philippe Bidet P, Kitzis MD, Gressens P, Bingen E, Stéphane Bonacorsi S. Effect of moxifloxacin combined with cefotaxime compared to cefotaxime-gentamicin combination on prevention of white matter damage associated with Escherichia coli sepsis in neonatal rats. Antimicrob Agents Chemother. 2011;55(7):3567-9.

3. Perdue PW, Kazarian KK, Nevola J, Law WR, Williams T. The use of local and systemic antibiotic in rat fecal peritonitis. J Surg Res. 1994;57:360-5.

4. Ablan CJ, Olen RN, Dobrin PB, ÒKeefe P, Tatarowicz W, Freeark RJ. Efficacy of intraperitoneal antibiotics in treatment of severe fecal peritonitis. Am J Surg. 1991;162:453-6.

5. Vallance S, Waldron R. Antiseptic vs. saline lavage in purulent and faecal peritonitis. J Hosp Infect. 1985;6:87-91.

6. Platt J, Jones RA, Bucknall RA. Intraperitoneal antiseptics in experimental bacterial peritonitis. Br J Surg. 1984;71:626-8.

7. Iakovlev SV, Ramishvili VSh, Nazarov VV, Eremina LV. Efficacy of moxifloxacin in the treatment of secondary peritonitis. Antibiot Khimioter. 2006;51(5):3-10.

8. Sikkink CJ, de Man B, Bleichrodt RP, van Goor H. Auto-cross-linked hyaluronic acid gel does not reduce intra-abdominal adhesions or abscess formation in a rat model of peritonitis. J Surg Res. 2006;136(2):255-9.

9. Carvalho CBGM, Petroianu A, Rodrigues FHOC, Rocha RF. Estudo comparativo entre diversos tipos de tratamento para peritonite fecal em rato. Rev Col Bras Cir. 2002;29(1):43-8.

10. Freitas LL, Soriano E, Muccioli C, Höfling-Lima AL, Belfort Jr R. Efficacy and tolerability of a combined moxifloxacin/dexamethasone formulation for topical prophylaxis and reduction of inflammation in phacoemulsification: a comparative, double masked clinical trial. Curr Med Res Opin. 2007;23(12):3123-30.

11. Espiritu CR, Sy ME, Tayengco TL. Efficacy and tolerability of a combined moxifloxacin/dexamethasone formulation for topical prophylaxis in phacoemulsification: an open-label single-arm clinical trial. J Ophthalmol. 2011;2011:769571.

12. Campos M, Ávila M, Belfort Jr R. Efficacy and tolerability of a fixed-dose moxifloxacin - dexamethasone formulation for topical prophylaxis in LASIK: a comparative, double-masked clinical trial. Clin Ophthalmol. 2008;2(2):331-8.

13. Solomkin J, Zhao YP, Ma EL, Chen MJ, Hampel B; DRAGON Study Team. Moxifloxacin is non-inferior to combination therapy with ceftriaxone plus metronidazole in patients with communityorigin complicated intra-abdominal infections. Int $\mathrm{J}$ Antimicrob Agents. 2009;34(5):439-45.

14. Mu YP, Liu RL, Wang LQ, Deng X, Zhu N, Wei MD, Wang Y. Moxifloxacin monotherapy for treatment of complicated intraabdominal infections: a meta-analysis of randomized controlled trials. Int J Clin Pract. 2012;66(2):210-7. 
15. Uddin MN, Siddiq A, Oettinger CW, D’Souza MJ. Potentiation of pro-inflammatory cytokine suppression and survival by microencapsulated dexamethasone in the treatment of experimental sepsis. J Drug Target. 2011;19(9):752-60.

16. Stass H, Rink AD, Delesen H, Kubitza D, Vestweber KH. Pharmacokinetics and peritoneal penetration of moxifloxacin in peritonitis. J Antimicrob Chemother. 2006;58(3):693-6.

17. Prausnitz MR, Noonan JS. Permeability of cornea, sclera, and conjunctiva: a literature analysis for drug delivery to the eye. J Pharm Sci. 1998;87(12):1479-88.

18. Farkas E, Luiten PG, Bari F. Permanent, bilateral common carotid artery occlusion in the rat: a model for chronic cerebral hypoperfusionrelated neurodegenerative diseases. Brain Res Rev. 2007;54:162-80.

19. Otori T, Katsumata T, Katayama Y, Terashi A. Measurement of regional cerebral blood flow and glucose utilization in rat brain under chronic hypoperfusion conditions following bilateral carotid artery occlusion. Analyzed by autoradiographical methods. Nippon Ika Daigaku Zasshi. 1997;64:428-39.

20. Gadelha DNB, Melo MCSC, Oliveira TKB, Brandt CT. Autogenous fecal peritonitis in Wistar rats with permanent bilateral carotid occlusion: morbidity, mortality and microbiological response. Acta Cir Bras. 2013;28(4):299-306.

21. Kayaoğlu HA, Ozkan N, Yenidoğan E, Köseoğlu RD. Effect of antibiotic lavage in adhesion prevention in bacterial peritonitis. UlusTravma Acil Cerrahi Derg. 2013;19(3):189-94.

22. Blot S, De Waele JJ, Vogelaers D. Essentials for selecting antimicrobial therapy for intra-abdominal infections. Drugs. 2012;72 (6):17-32.

23. Shi G, Chen X, Wang H, Wang S, Guo X, Zhang X. Activity of sitafloxacin against extracellular and intracellular Staphylococcus aureus in vitro and in vivo: comparison with levofloxacin and moxifloxacin. J Antibiot (Tokyo). 2012;65(5):229-36.

24. Weiss G, Reimnitz P, Hampel B, Muehlhofer E, Lippert H. AIDA Study Group Moxifloxacin for the treatment of patients with complicated intra-abdominal infections (the AIDA Study). J Chemother. 2009;21(2):170-80.

25. Rink AD, Stass H, Delesen H, Kubitza D, Vestweber KH. Pharmacokinetics and tissue penetration of moxifloxacin in intervention therapy for intra-abdominal abscess. Clin Drug Investig. 2008;28(2):71-9.

26. Cisneros $\mathrm{R}$, Onderdonk AB. Antimicrobial efficacy testing of moxifloxacin during the peritonitis and abscess formation stages of intra-abdominal sepsis: a controlled trial in the rat model. Curr Ther Res. 2002;63(12):821-7.

27. Brunkhorst FM, Oppert M, Marx G, Bloos F, Ludewig K, Putensen C, Nierhaus A, Jaschinski U, Meier-Hellmann A, Weyland A, Gründling M, Moerer O, Riessen R, Seibel A, Ragaller M, Büchler MW, John S, Bach F, Spies C, Reill L, Fritz H, Kiehntopf M, Kuhnt E, Bogatsch H, Engel C, Loeffler M, Kollef MH, Reinhart K, Welte T; German Study Group Competence Network Sepsis (SepNet). Effect of empirical treatment with moxifloxacin and meropenem vs meropenem on sepsis-related organ dysfunction in patients with severe sepsis: a randomized trial. JAMA. 2012;307(22):2390-9.

28. Le Saché N, Baud O, Pansiot J, Pham H, Biran V, Brunel-Meunier N, Bidet P, Kitzis MD, Gressens P, Bingen E, Charriaut-Marlangue
C, Bonacorsi S.Effect of moxifloxacin combined with cefotaxime compared to cefotaxime-gentamicin combination on prevention of white matter damage associated with Escherichia coli sepsis in neonatal rats. Antimicrob Agents Chemother. 2011;55(7):3567-9.

29. Li GM, Ji MH, Sun XJ, Zeng QT, Tian M, Fan YX, Li WY, Li N, Yang JJ. Effects of hydrogen-rich saline treatment on polymicrobial sepsis. J Surg Res. 2013;181(2):279-86.

30. Kreimer F, Aguiar JLA, Castro CMMB, Lacerda CM, Reis T, Lisboa Júnior F. Resposta terapêutica e inflamatória de ratos com peritonite secundária submetidos ao uso tópico de ampicilina/sulbactam. Acta Cir Bras. 2005;20(1):31-9.

31. Brocco MC, Paulo DN, Baptista JF, Carraretto AR, Ferrari TA, de Azevedo TC, da Silva AL Effects of peritoneal lavage with bupivacaine on survival of mice with fecal peritonitis. Rev Bras Anestesiol. 2008;58(5):470-9.

32. Brocco MC, Gomez RS, Paulo DN, Almeida CE, Baptista JF. Histological features of peritoneal lavage with ropivacaine in rats with fecal peritonitis. Acta Cir Bras. 2012;27 (2):193-9.

\section{Correspondence:}

Carlos Teixeira Brandt

Avenida Boa Viagem, 5030/1302

51011-000 Recife - PE Brasil

Tel.: (55 81)3342-0830

carlosbrandt@bol.com.br

Received: Oct 17, 2013

Review: Dec 18, 2013

Accepted: Jan 20, 2014

Conflict of interest: none

Financial source: Medical Sciences, Faculty of Campina Grande

${ }^{1}$ Research performed at Experimental Research Unit, Campina Grande Medical School (FCM), Campina Grande-PB, Brazil. 